Résumés des conférences et travaux

\title{
Sources et méthodes de l'histoire des relations internationales dans l'Europe médiévale
}

\section{Stéphane Péquignot}

\section{OpenEdition}

\section{Journals}

Édition électronique

URL : https://journals.openedition.org/ashp/1309

DOI : 10.4000/ashp.1309

ISSN : 1969-6310

\section{Éditeur}

Publications de l'École Pratique des Hautes Études

\section{Édition imprimée}

Date de publication : 1 octobre 2012

Pagination : 174-176

ISSN : 0766-0677

\section{Référence électronique}

Stéphane Péquignot, « Sources et méthodes de l'histoire des relations internationales dans l'Europe médiévale », Annuaire de l'École pratique des hautes études (EPHE), Section des sciences historiques et philologiques [En ligne], 143 | 2012, mis en ligne le 24 septembre 2012, consulté le 03 août 2021. URL http://journals.openedition.org/ashp/1309; DOI : https://doi.org/10.4000/ashp.1309 


\title{
SOURCES ET MÉTHODES DE L'HISTOIRE DES RELATIONS INTERNATIONALES DANS L'EUROPE MÉDIÉVALE
}

\author{
Maître de conférences : M. Stéphane PÉQuignot
}

Programme de l'année 2010-2011: I. Les diplomaties médiévales: approches historiographiques. - II. Commynes et l'Espagne.

\section{Les diplomaties médiévales : approches historiographiques}

Une grande partie du séminaire a été consacrée à la poursuite de l'étude comparée des ambassades ad hoc en Occident du IX ${ }^{\mathrm{e}}$ au XV siècle. Après avoir en 2009-2010 dressé un bilan historiographique général sur la question et examiné les pratiques de l'époque carolingienne, le travail a cette année porté plus particulièrement sur une période souvent délaissée par l'histoire de la diplomatie, les $\mathrm{X}^{\mathrm{e}}-\mathrm{XII}^{\mathrm{e}}$ siècles. Avec le souci de saisir au sein d'une matière très riche des évolutions de longue durée, l'analyse s'est concentrée sur les ambassades expédiées et reçues alors par les empereurs. Un état général des sources disponibles a tout d'abord permis de rappeler la disparité des fonds susceptibles d'éclairer les échanges diplomatiques respectifs des empereurs de Byzance, des Ottoniens, des Saliens et des Staufen, les difficultés souvent éprouvées à percevoir les modalités concrètes de négociation, la relative parcimonie en Occident des prescriptions normatives concernant les ambassades, mais aussi, à partir du $\mathrm{XII}^{\mathrm{e}}$ siècle, la meilleure conservation d'actes de la pratique devenus plus nombreux. La discussion de la production historiographique a ensuite conduit à souligner l'absence de synthèses récentes sur les ambassades aux $\mathrm{X}^{\mathrm{e}}$-XII ${ }^{\mathrm{e}}$ siècles - sur bien des aspects, il est encore nécessaire de se référer à V. Menzel, Deutsches Gesandtschaftswesen im Mittelalter, 1892, à F.-L. Ganshof, Histoire des relations internationales. Le Moyen Âge, 1953 ou à D. E. Queller, The Office of the Ambassador in the Middle Ages, 1967. Ont ensuite été mis en perspective les apports récents et dispersés en ce domaine, notamment les travaux qui ont envisagé les ambassades comme un mode de communication (par exemple V. Scior, « Bemerkungen zum frühmittelalterlichen Boten- und Gesandtschaftswesen », dans Der Staat im Frühmittelalter, 2009), les études répétées sur des ambassades particulièrement spectaculaires, comme celle de Liutprand de Crémone à Byzance, et les nombreuses analyses éclairant les relations des Empires avec des puissances étrangères. En dépit de quelques résultats marquants (W. Georgi, « Legatio virum sapientem requirit. Zur Rolle der Erzbischöfe von Köln als königlichkaiserliche Gesandte ", dans Köln. Stadt und Bistum in Kirche und Reich des Mittelalters. Festschrift für Odilo Engels, éd. H. Vollrath et S. Weinfurter, 1993, p. 61-124), il s'est avéré au terme de cette présentation que les recherches spécialisées sur les ambassades et les ambassadeurs demeuraient encore trop rares pour les $\mathrm{X}^{\mathrm{e}}$-XII ${ }^{\mathrm{e}}$ siècles.

Plusieurs sources essentielles sur la pratique des ambassades ont ensuite été commentées en séminaire : un chapitre de la Vita de Jean de Gorze relatant son ambassade 
auprès du calife de Cordoue Abd al-Rahman III au sein d'un dispositif hagiographique dans lequel la mission constitue une véritable épreuve religieuse pour l'ambassadeur; le Liber rerum gestarum Saxonicarum de Widukind de Corvey, pour lequel les ambassades reçues par les rois des Saxons forment un motif récurrent de la manifestation de la puissance des souverains, et la Chronique de Thietmar de Mersebourg, intéressé surtout par les ambassadeurs des princes ou des villes qui ne respectent pas leur rôle. La période des Staufen a ensuite été envisagée au prisme de l'œuvre d'Otton de Freising. Une dizaine de mentions d'ambassades figurent dans sa Chronica sive Historia de duabus civitatibus, tandis que les Gesta Friderici (complétées par son élève Rahewin) abritent dans les livres II, III et IV vingt-neuf chapitres centrés sur des affaires diplomatiques. Un commentaire détaillé des chapitres XXIX-XXXI du livre II a par exemple fait ressortir le caractère éminemment sensible des ambassades pour l'autorité et la dignité impériales, et comment elles constituent souvent un cadre exemplaire susceptible de révéler la nature antagoniste des pouvoirs mis en relation. Les ambassadeurs de Rome et du Sénat envoyés à Frédéric Barberousse usent ainsi selon Otton d'une rhétorique excessive en prononçant des discours more italico surchargés de longues périodes, des verba [...] plus arrogantiae tumore insipida quam sale sapientiae condita ; tandis que Frédéric s'exprime pour sa part en paroles mesurées, claires, brèves.

Les différents éléments réunis dans cette partie de l'enquête ont abouti à un premier bilan comparatif, encore provisoire, sur l'évolution des usages de l'ambassade par les pouvoirs impériaux depuis les Carolingiens jusqu'à la fin du XII ${ }^{\mathrm{e}}$ siècle. La faible différenciation des termes utilisés pour désigner les messagers et les ambassadeurs (legati, missi, nuntii) et l'absence de distinction nette entre le messager et l'ambassadeur se maintiennent largement. D'autres termes sont néanmoins utilisés (internuntii par exemple chez Widukind de Corvey), on observe une certaine spécialisation du terme legatus, de plus en plus employé pour qualifier des représentants du pape et de l'empereur avec une spécification de leur territoire de compétence, l'usage du terme générique de nuntius se développe et, à l'extrême fin de la période, le terme ambaxiator revêt le sens d'ambassadeur en Italie du Nord. Les compétences et le statut des ambassadeurs connaissent également une lente évolution. La place des laïcs s'accroît, mais, s'il existe des experts reconnus (Liutprand de Crémone, Godefroy de Viterbe par exemple), la «spécialisation » des ambassadeurs au cours du $\mathrm{XII}^{\mathrm{e}}$ siècle présente encore un caractère limité. Enfin, la comparaison des différents mobiles du recours aux ambassades, de leurs modalités de déroulement et, surtout, de la valeur souvent très grande accordée aux incidents diplomatiques, a fait ressortir le rôle important joué par les ambassades dans la consolidation du caractère impérial des pouvoirs. Cela se manifeste par une conception et une pratique compétitive des cadeaux et des rituels, par un usage inégalitaire de l'ambassade, qui exprime tantôt la soumission ou la déférence, tantôt la supériorité, mais aussi, durant toute la période, par l'énumération des ambassadeurs étrangers à la cour en guise de marque de supériorité, ou bien encore, à partir du XII ${ }^{\mathrm{e}}$ siècle, par l'interprétation des atteintes portées aux représentants de l'empereur comme des crimes de lèse-majesté. De ce point de vue, les modèles de comportement impérial observés présentent alors pour la gestion des ambassades de fortes similitudes. 
Dans le cadre de cette approche comparée des ambassades ad hoc, une étude de cas a été menée à une échelle plus restreinte sur les échanges diplomatiques effectués en péninsule Ibérique durant le règne d'Alphonse VI, roi de Castille de 1072 à 1109, imperator totius Hispaniae. Deux sources principales ont été convoquées : la Chronica Naierensis, dans laquelle l'ambassade est une pratique utilisée autant par les chrétiens que par les musulmans, puis le Cantar de Mio Cid. En ce dernier cas, situé à la frontière des relations diplomatiques - le Cid dispose d'un pouvoir autonome en pratique, mais est soucieux de rétablir un lien de vassalité dénoncé par son roi -, l'étude des échanges de messagers et de mandataires (mensajeros, mandaderos) révèle à la fois la porosité de la pratique de l'ambassade, parfois difficile à isoler des échanges entre suzerains et vassaux, et l'omniprésence des messagers dans la vie de sociétés marquées par l'expérience des combats frontaliers.

\section{Commynes et l'Espagne}

Dans cette deuxième partie du séminaire, beaucoup plus brève, il s'est agi de Philippe de Commynes et, plus précisément, de ses rapports complexes avec l'Espagne. À la lecture de ses Mémoires et de ses Lettres, complétée par celle de correspondances diplomatiques et de chroniqueurs contemporains, l'expérience personnelle de l'Espagne par Philippe de Commynes reste probable, mais ne peut être prouvée de façon définitive. L'hypothèse la plus plausible demeure qu'il aurait, à un moment de tensions entre Charles le Téméraire et Louis XI, été envoyé par le duc de Bourgogne en Castille afin d'effectuer des sondages auprès du roi Henri IV. Quoi qu'il en soit, les passages de ses écrits relatifs à la péninsule Ibérique et la comparaison avec les discours historiographiques contemporains tenus sur l'Espagne par Thomas Basin, Mathieu d'Escouchy, Olivier de la Marche et Georges Chastellain ont permis de montrer une bonne connaissance des réalités ibériques par Commynes, qui s'avère particulièrement sensible aux mutations des pouvoirs et à l'émergence de nouveaux antagonismes outre-Pyrénées. Par la suite, les inventaires de bibliothèques publiés, les témoignages de quelques grands historiens - notamment l'aragonais Jerónimo Zurita - et les premières traductions en espagnol des Mémoires attestent d'une circulation importante et variée de l'œuvre de Commynes dans l'Espagne du XvI ${ }^{\mathrm{e}}$ siècle. 